\title{
Editorial
}

\section{Nuevas técnicas de adquisición y tratamiento de imágenes para el desarrollo de la instrumentación biomédica: Impacto social en el sector salud}

\author{
DRA. JULY ANDREA GALEANO ZEA \\ Université de Franche-Comté \\ Besancon-France
}

En la actualidad, instituciones de carácter gubernamental y privado ofrecen financiamiento económico en investigaciones científicas y tecnológicas dedicadas a la mejora de las áreas de mayor impacto en la sociedad, donde la salud es una de estas. Aunque la salud también está relacionada con el estado de completo bienestar físico/mental, y no solamente a la ausencia de afecciones o enfermedades, aquí centraremos la discusión en la investigación relacionada con las enfermedades humanas. En este campo, algunas instituciones gubernamentales han establecido áreas prioritarias de salud entre las cuales el cáncer es una de ellas. El cáncer es una de las enfermedades que tiene un gran impacto en la comunidad en términos de morbilidad, mortalidad y costos. Por ejemplo en Colombia, en el año 2006, 13,9\% de las defunciones en hombres y $19,3 \%$ de las muertes en mujeres fueron por cáncer (Piñeros et al., 2011).

Durante las últimas décadas, la ciencia y la tecnología desempeñan un papel cada vez más importante en el área de la salud. Nuevos avances en cuanto a prevención, detección temprana, cirugía y tratamiento de enfermedades son reportados regularmente. Este es el caso de la investigación relacionada con la instrumentación biomédica, donde gracias a su creciente desarrollo se han reportado avances en el estudio de enfermedades humanas para el descubrimiento de nuevos fármacos o tratamientos.

La instrumentación biomédica hace así referencia a equipos terapéuticos, e instrumentos de medición, registro y control. Asimismo, se refiere a los sistemas de imágenes modernas como en radiología, medicina nuclear, endoscopia, termografía, fotografía 
médica y microscopía. El creciente desarrollo de instrumentos biomédicos ha hecho que algunos de ellos sean inclusive prerequisito esencial de medida en cualquier procedimiento biomédico. Como ejemplo se puede nombrar el microscopio, un antiguo instrumento que se ha convertido prioritario en muchos protocolos biológicos. Debido al alto impacto que tiene la instrumentación biomédica en el área de la salud, nuevos medios especializados han surgido entre las disciplinas científicas tradicionales, como la ingeniería y la física, cuyo interés se centra en el estudio y la investigación de nuevos instrumentos o incluso en la mejora de los ya existentes.

Como ejemplo, podemos encontrar diferentes grupos en el área de la óptica y la informática cuya actividad específica es el estudio de nuevo instrumentos de adquisición y análisis de imágenes. Estos instrumentos, junto con técnicas computacionales, tienen como objetivo principal darles a los médicos una nueva guía para la discriminación de enfermedades. Así, técnicas basadas en imágenes multi-espectrales junto con métodos estadísticos prometen ser una herramienta en el análisis de patologías cutáneas (Galeano et al., 2012). Igualmente, el uso de algoritmos como redes neuronales o algoritmos evolucionarios pueden ser utilizados para discernir en un tejido las áreas cancerígenas de las áreas sanas.

Otro ejemplo a citar es el desarrollo de nuevas técnicas de microscopia que permiten tener imágenes con resoluciones de menos de un micrómetro, permitiendo a los biólogos observar nuevos estructuras intracelulares que permitan dar nuevos indicios para el mejor entendimiento de patologías. Algunas de estas técnicas son STED (Stimulation Emission Depletion), STORM (Stochastic Optical Reconstruction Microscopy), PALM (Photoactivated Localization Microscopy), entre otras.

En conjunto con los recientes avances en microscopia, surge la necesidad de técnicas para la manipulación o rastreo de cuerpos microscópicos. Así, tenemos como ejemplo una nueva técnica basada en tratamiento de imágenes que permite el posicionamiento absoluto con alta resolución (del orden de nanómetros) de zonas de interés de un objeto bajo análisis. La anterior técnica ha permitido el seguimiento de la evolución de eventos celulares tales como la 
internalización de cuerpos apoptóticos (cuerpos celulares portadores de ADN cancerígeno) por células sanas (Galeano et al., 2011).

Finalmente, el desarrollo de nuevas técnicas en adquisición de imágenes ha promovido a que los investigadores exploren en la combinación de métodos ya existentes. Como ejemplo tenemos el desarrollo de nuevas técnicas de endoscopia basadas en microscopia confocal o en técnicas OCT (Optical Coherence Tomography). Lo anterior implica un gran reto en cuanto a la miniaturización de los elementos conllevando así a avances en el área de la microtecnología para el desarrollo de nuevos sistemas Opto-Mecatrónicos (MOEMS: Micro-Opto-ElectroMechanical systems).

En conclusión, vemos como el campo de la instrumentación biomédica reúne diferente disciplinas que trabajando de forma conjunta conllevan a avances que permiten un impacto positivo en la sociedad.

\section{Referencias}

Galeano, J.A., Sandoz, P., Gaiffe, E., Launay, S., Robert, L., Jacquot, M., Hirchaud, F., Pretet, J.L., Mougin, C. (2011). Position-referenced microscopy for live cell culture monitoring, Biomed Opt Express, 2(5), 1307-1318.

Galeano, J.A., Jolivot, R., Marzani, F. (2012). Quantification of Melanin and Hemoglobin in Human Skin from Multispectral Image Acquisition: Use of a Neuronal Network Combined to a Non-Negative Matrix Factorization, Applied and Computational Mathematics, 11(2), 257-270.

Piñeros, M., Murillo, R., Porras, A. (2011). Guía para el análisis de la situación del cáncer. Ministerio de la protección Social, Instituto Nacional de Cancerología. Series de documentos técnicos INC No. 4. Bogotá-Colombia. 